\title{
Analysis of Compressive Toughness and Deformability of High Ductile Fiber Reinforced Concrete
}

\author{
Mingke Deng, Jian Han, Haibo Liu, Meng Qin, and Xingwen Liang \\ School of Civil Engineering, Xi'an University of Architecture and Technology, Xi'an 710055, China \\ Correspondence should be addressed to Mingke Deng; dengmingke@126.com
}

Received 27 June 2015; Accepted 11 October 2015

Academic Editor: Carlo Santulli

Copyright ( 2015 Mingke Deng et al. This is an open access article distributed under the Creative Commons Attribution License, which permits unrestricted use, distribution, and reproduction in any medium, provided the original work is properly cited.

\begin{abstract}
The compressive toughness evaluation index of HDC (high ductile fiber reinforced concrete) is studied through three groups of uniaxial compressive tests of HDC specimens with different fiber mixing amounts, and an equivalent analysis of their deformability is carried out, coming to the following conclusion: (1) the peak strain of HDC under uniaxial compression can be up to 3.41 3.67 times as large as that of the mortar matrix; (2) the equivalent compressive toughness index reflects the unit volume deformation energy of specimens under uniaxial compression and it can be used as the compressive toughness evaluation index of HDC; (3) the fiber bridging effect of HDC increases the equivalent compressive toughness index and the compressive deformability up to 3 times of the mortar matrix; (4) the relationship between the equivalent compressive toughness index $W_{c u}^{0.85}$ and the fiber mixing amount $\varphi$ is established according to the test results; and (5) the fiber bridging effect of the matrix in HDC can be equaling as a large number of constraint stirrups installed in the specimens, which significantly enhances the compressive toughness and the compressive deformability of specimens.
\end{abstract}

\section{Introduction}

Engineered cementitious composite [1] (ECC) is a kind of new structural material with high toughness, high crack resistance property, and damage resistance property, which was first proposed in the 1990s by Li, a Professor of University of Michigan, United States. ECC, showing good multiple cracking and strain hardening under direct tension and shear load, can significantly improve the toughness and resistance property of concrete and has an extensive application prospect in the field of civil engineering. Li et al. proposed a micro mechanical model of ECC by studying the characteristics of fiber, matrix, and interface [2]; Gong and Zhang studied the effect of PVA fiber diameter on the crack resistance property of ECC [3]; Zhang et al. studied the influence of matrix strength (water-binder ratio) on the bending resistance property of ECC [4]; Pang et al. studied the effect of fly ash amount, cement-sand ratio, and the like on the mechanical properties of ECC [5]; Li and Xu studied the bending resistance property and flexural toughness evaluation method of ultra high toughness cementitious composite (UHTCC) [6]. In order to facilitate the application of ECC in concrete structures, this research team referred to it as high ductile fiber reinforced concrete (HDC) and systematically carried out tests on compressive property, bending resistance property, and size effect of high ductile fiber reinforced concrete $[7,8]$.

The axial compressive property is one of basic mechanical indices of concrete. The failure of ordinary concrete under compression shows clear brittleness, while HDC represents good toughness and damage resistance property, so its compressive toughness also becomes an important mechanical property index. Toughness reflects the property of a material to absorb energy and resist fractural damage. When a matrix cracks, fiber will consume more energy to overcome the interface friction so that it can be pulled out from the matrix, thus making HDC have good integrity after cracking. Cai and $\mathrm{Xu}$ conducted the tests and evaluation work of UHTCC's uniaxial compressive toughness [9]. Xu et al. concluded from uniaxial compressive tests that the plastic deformation property and peak ductility of UHTCC are obviously better than those of concrete [10].

For further study of HDC's compressive toughness and deformability, prism specimens with the measurement of 
Table 1: Properties of PVA fiber.

\begin{tabular}{lcccccc}
\hline Length $/ \mathrm{mm}$ & Diameter $/ \mu \mathrm{m}$ & Aspect ratio & Tensile strength/MPa & Elasticity modulus/GPa & Ultimate strain/\% & Density/(g/cm $\left.{ }^{3}\right)$ \\
\hline 12 & 39 & $0.31 \times 10^{3}$ & 1600 & 40 & 7 & 1.3 \\
\hline
\end{tabular}

TABLe 2: Mix of test.

\begin{tabular}{lcccc}
\hline Code & Water-cement ratio & Fiber (by volume) $/ \%$ & Fly ash (by volume)/\% & Sand-cement ratio \\
\hline 1 & 0.29 & 0 & 50 & 0.36 \\
2 & 0.29 & 1.0 & 50 & 0.36 \\
3 & 0.29 & 1.5 & 50 & 0.36 \\
4 & 0.29 & 2.0 & 50 & 0.36 \\
\hline
\end{tabular}

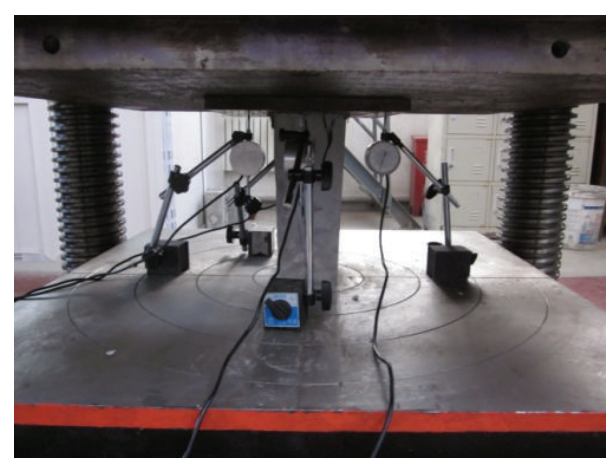

Figure 1: Test loading device.

$100 \mathrm{~mm} \times 100 \mathrm{~mm} \times 300 \mathrm{~mm}$ are selected in this paper, and three groups of uniaxial compressive tests of HDC specimens with different fiber mixing amounts are conducted to obtain an evaluation method for determining the compressive toughness of HDC and to provide the basis for the engineering application of HDC.

\section{Test Overview}

2.1. Specimen Design and Test Methods. High ductile fiber reinforced concrete used in tests is basically composed of cement, fly ash, fine river sand, PVA fiber, water, and superplasticizer. Specific parameters of PVA fiber are shown in Table 1; the test mixture proportions are shown in Table 2, and mixture proportion 1 indicates a comparison specimen of cement mortar matrix without fiber.

Each test contains three prism specimens with the measurement of $100 \mathrm{~mm} \times 100 \mathrm{~mm} \times 300 \mathrm{~mm}$. All specimens are produced and maintained in the same condition. The test age is 10 months, loaded by $500 t$ electrohydraulic servo pressure machine with the loading rate of $0.5 \mathrm{~mm} / \mathrm{min}$. The test loading device is shown in Figure 1.

2.2. Test Phenomena. The compressive damage process of mortar matrix is similar to that of ordinary concrete. The specimens lost their bearing capacity upon the appearance of vertical cracks.

The compressive damage process of high ductile fiber reinforced concrete is very different with mortar matrix,
TABLE 3: Test results.

\begin{tabular}{lccc}
\hline Mix & Peak load $(\mathrm{kN})$ & Peak deformation $(\mathrm{mm})$ & Peak strain \\
\hline 1 & 640.45 & 0.65 & 0.0022 \\
2 & 502.78 & 2.22 & 0.0074 \\
3 & 568.50 & 2.02 & 0.0067 \\
4 & 622.52 & 2.39 & 0.0080 \\
\hline
\end{tabular}

including no-crack stage, crack's stable development stage, and crack's unstable development stage, which are described in detail as follows.

At the beginning of loading, there is a small transverse deformation of the specimen; the stress-strain curve shows a linear relationship; and the specimen is in the elastic stage. At a loading of $50 \sim 60 \%$ of the ultimate load, the transverse deformation of the specimen enlarges; vertical micro cracks start to appear on the surface; the growth of matrix internal cracks is confined to some extent by fiber bridging effect; the stress-strain curve basically shows a linear relationship; and the specimen is still in the elastic stage. At a loading of $80 \%$ or above of the ultimate load, surface cracks of the specimen are gradually widening, the growth rate of strain is higher than that of stress, and the stress-strain curve bends; a main crack comes into being vertically along the specimen; and the $t$ sounds of fiber pulled out or snapped off can be heard with the main crack widening. After the specimen reaches the ultimate load, the main crack suddenly becomes wider; the bearing capacity decreases; and the deformation of the specimen continues to increase. When the loading decreases to $10 \sim 20 \%$ of the ultimate load, there is obvious dislocation on both sides of the specimen's main crack, and the bearing capacity of the specimen decreases slowly. The specimen has always maintained certain residual bearing capacity after the damage. The crack shapes of all specimens after compressive failure are shown in Figure 2.

\section{Test Results and Analyses}

3.1. Uniaxial Compressive Load-Deformation Curve. Uniaxial compressive load-deformation curves of each group of specimens are as shown in Figure 3. Table 3 gives the ultimate load and peak deformation of each group of specimens.

As can be seen from Figure 3 and Table 3, the strain corresponding to peak load of mortar matrix (with a mixture 


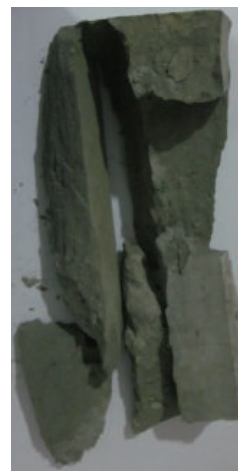

(a) Mortar matrix

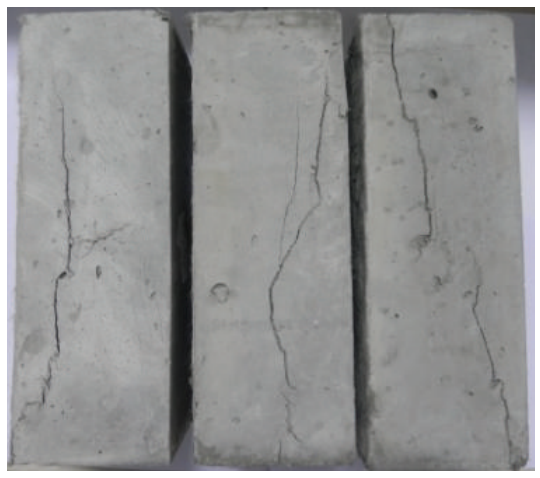

(b) Peak load failure mode

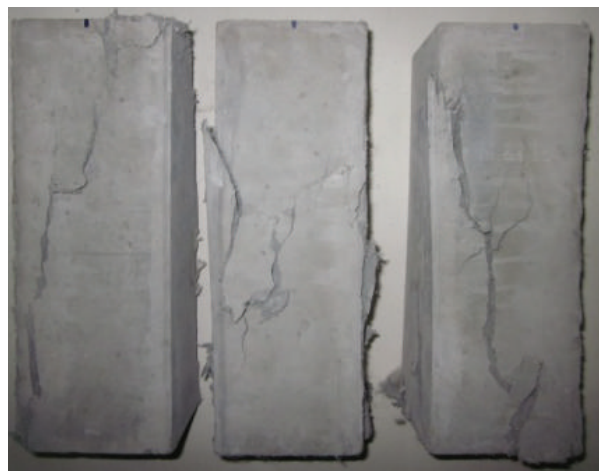

(c) Ultimate failure mode

FIGURE 2: Failure mode of test specimens.
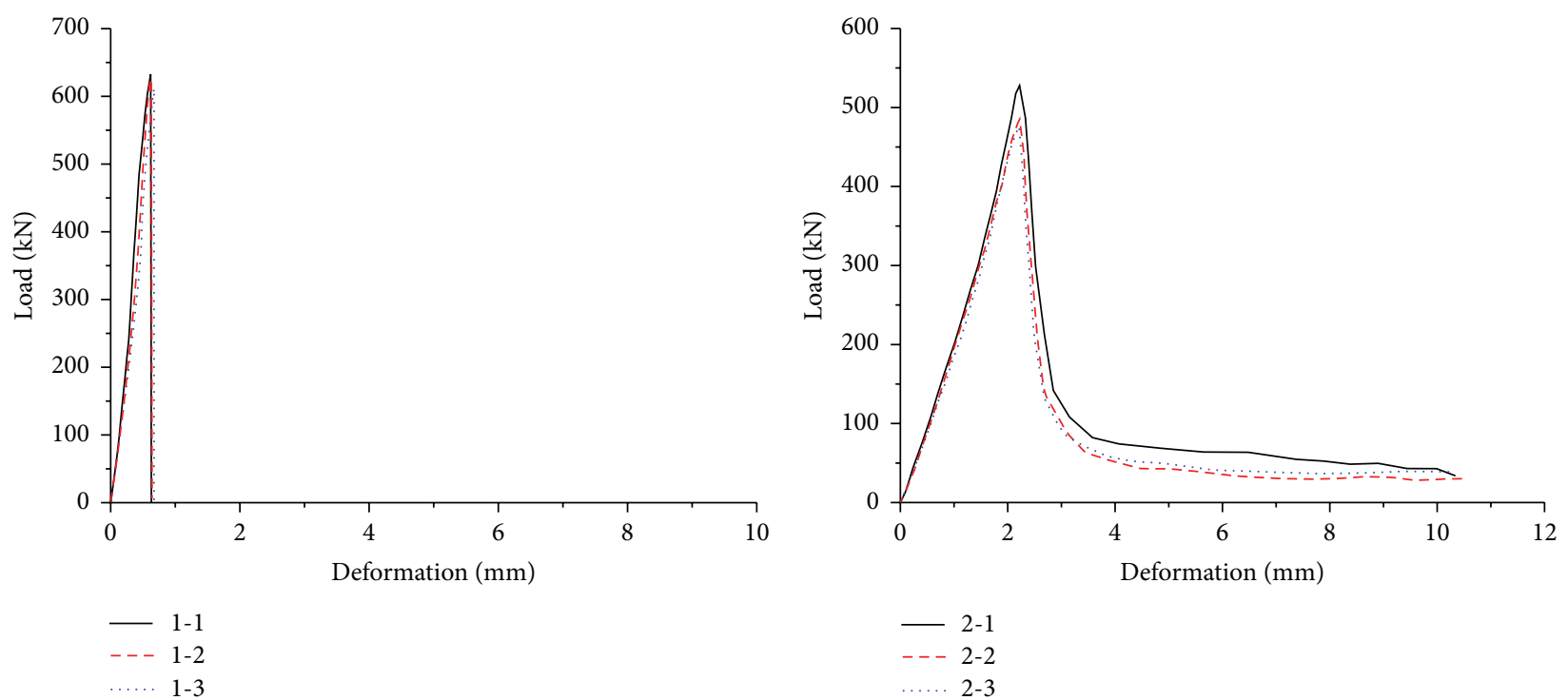

$---2-2$

..... $2-3$

(a) Matrix block-mix 1
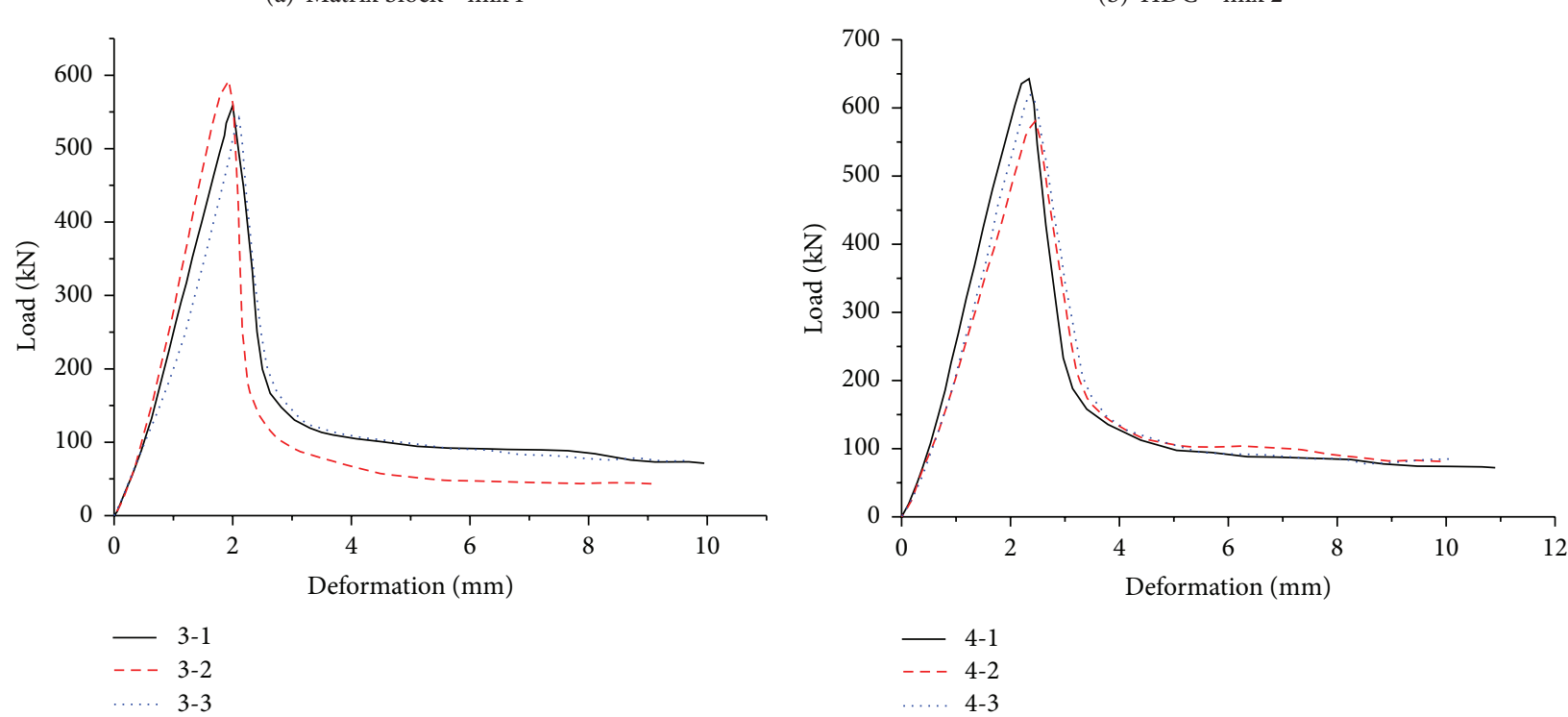

(c) HDC-mix 3

(d) HDC-mix 4

FIGURE 3: The uniaxial compressive load-deformation curve of test specimens. 
proportion 1) is 0.0022 , which is close to the peak strain of corresponding concrete stipulated in Code for design of concrete structures [11]. The uniaxial compressive loaddeformation curve of high ductile fiber reinforced concrete is a single-peak curve, with its peak deformation significantly increased when compared with the mortar matrix specimen. Peak deformations of three groups of HDC specimens with different fiber mixing amounts are up to 3.41 3.67 times as large as that of the mortar matrix, thus showing that the deformation strength of HDC has obviously improved before it reaches the ultimate load. The fiber mixing amount has less effect on the strength of specimens but has greater influence on the deformation ability; when the fiber mixing amount exceeds $1 \%$, there is little increase in the peak strain of HDC specimens. In addition, HDC specimens still have good integrity after compressive damage and have 10 $20 \%$ of residual bearing capacity during larger compressive deformations.

3.2. Analysis of Compressive Toughness Index. The calculation method of equivalent bending strength $f_{e}$ is stipulated in Standard Test Methods For Fiber Reinforced Concrete [12] in China as follows:

$$
f_{e}=\frac{\Omega_{k} L}{b h^{2} \delta_{k}}
$$

In the formula, $f_{e}$ means the equivalent bending strength (MPa); $\Omega_{k}$ means the area under the load-deflection curve with the midspan deflection as $L / 150(\mathrm{~N} \cdot \mathrm{mm})$; and $\delta_{k}$ means the deflection value with the midspan deflection as $L / 150$.

According to the calculation method of equivalent bending strength and the uniaxial compressive load-deformation curve of HDC specimen, the calculation method of equivalent compressive strength (Figure 4) is proposed as follows:

$$
f_{c e}=\frac{P}{A}=\frac{\Omega_{u}}{\delta_{u} A} .
$$

In the formula, $P$ refers to the axial pressure $(\mathrm{N}) ; f_{c e}$ refers to the equivalent compressive strength $(\mathrm{MPa}) ; \Omega_{u}$ refers to the area under the load-deformation curve with the vertical deformation as $\delta_{u}(\mathrm{~N} \cdot \mathrm{mm}) ; \delta_{u}$ refers to the corresponding vertical deformation when the load drops to $u$ times of the ultimate load $(0.85,0.50$, or 0.20 as desired) (mm); and $A$ refers to the uniaxial compressive area of the specimen.

Relevant to the compressive strength and deformability of a material, compressive toughness reflects the property of absorbing energy and resisting damage when the material is under compressive damage. The equivalent compressive strength calculated according to formula (2) reflects that the average compressive strength of the specimen corresponding to the bearing capacity drops to a certain value during a compressive damage, but it cannot effectively reflect the compressive toughness of the specimen for the influence of compressive deformation in the damage process is not considered.

To consider the influence of specimen deformation on compressive toughness, dimensionless ratio $\delta_{u} / l(l$ indicates

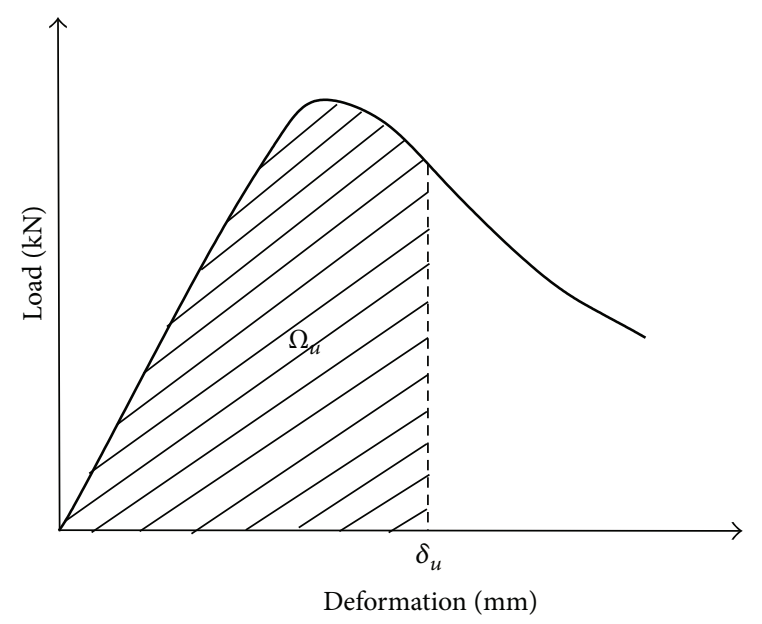

FIGURE 4: The calculation of equivalent compressive strength.

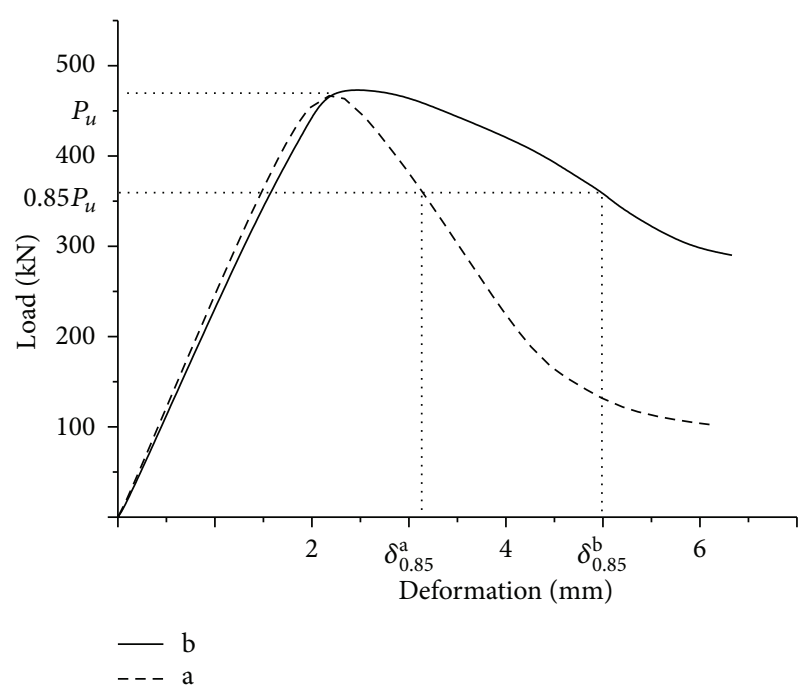

FIGURE 5: Comparative analysis of the different curves.

the specimen height) is adopted to revise formula (2) as follows:

$$
W_{c u}=f_{c e} \times \frac{\delta_{u}}{l}=\frac{\Omega_{u}}{\delta_{u} A} \times \frac{\delta_{u}}{l}=\frac{\Omega_{u}}{A l} .
$$

$W_{c u}$ is the equivalent compressive toughness index. As can be seen from formula (3), it is physical interpretation is per unit volume deformation energy of specimens under uniaxial compression, and it can be used as compressive toughness evaluation index of specimens.

In the following, uniaxial compressive load-deformation curves of specimens a and b (Figure 5) will be used as an example to further illustrate the physical meaning of the equivalent compressive toughness index. When $u$ is to be $0.85, \delta_{0.85}^{\mathrm{b}}$ in Figure 4 is 1.60 times as large as $\delta_{0.85}^{\mathrm{a}}$, showing that the compressive toughness of specimen $b$ is significantly higher than that of specimen a. According to formula (2), $f_{c e}^{\mathrm{b}} / f_{c e}^{\mathrm{a}}=1.06$ can be obtained; and, according to formula (3), $W_{c u}^{\mathrm{b}} / W_{c u}^{\mathrm{a}}=1.66$ can be obtained. Evidently, the equivalent 
compressive toughness index $W_{c u}$ comprehensively reflects the influence of compressive strength and deformability. Therefore, it can effectively reflect the compressive toughness of a specimen under uniaxial compression.

Based on the above test results, when $u$ is to be $0.85,0.50$, and 0.20 , respectively, the calculation results of equivalent compressive toughness index are shown in Table 4.

In Table $4, W_{c u}^{0.85}$ reflects the corresponding compressive toughness when the specimen's bearing capacity drops down to 0.85 times of the ultimate load and can be used in ductility and energy dissipation analysis of the structure; $W_{c u}^{0.50}$ and $W_{c u}^{0.20}$ reflect the corresponding compressive toughness when the specimen's bearing capacity drops down to 0.50 and 0.20 times of the ultimate load, respectively, and can be used in residual bearing capacity analysis of the structure design to resist successive collapses. When the fiber mixing amount exceeds $1 \%$, the compressive toughness index of HDC specimens improves obviously, with its growth rate significantly reduced.

3.3. Relationship between Compressive Toughness Index and Fiber Mixing Amount. The compressive damage of high ductile fiber reinforced concrete is obviously different from that of mortar matrix, mainly depending on PVA fiber randomly distributed in the matrix. Owing to the fiber bridging effect, longitudinal compression of the specimen is subject to some lateral restraint, and the stress state and deformability of HDC after cracking are improved, thus increasing the compressive toughness of the material.

As can be inferred from Tables 3 and 4, when the fiber mixing amount is changed, though the fiber bridging effect does not markedly increase the HDC uniaxial compressive strength, it can increase the compressive toughness index 2.88 4.09 times and the compressive deformability 3.41 3.67 times more than the mortar matrix does. Therefore, fiber mixing amount is a main factor affecting the compressive toughness index. For further analysis of the quantitative relationship between the fiber mixing amount and the compressive toughness index, the compressive toughness index in Table 4 that changes the fiber mixing amount is under a linear regression analysis, and the relationship between the equivalent compressive toughness index $W_{c u}^{0.85}$ and the fiber mixing amount $\varphi$ is shown in Figure 6, with its formula as

$$
W_{c u}^{0.85}=W_{c u, 0}^{0.85}+0.10 \varphi .
$$

In the formula, $W_{c u, 0}^{0.85}$ means the corresponding equivalent compressive toughness index when the bearing capacity of the matrix specimen drops to 0.85 times of the ultimate load.

3.4. Analysis of Specimen's Compressive Deformability. Due to the fiber bridging effect of high ductility fiber reinforced concrete, vertical cracks caused by longitudinal compression and deformations caused by lateral tension of the specimen are subject to balanced and continuous restraints. Therefore, the stress state of HDC under uniaxial compression equals confined concrete under the conventional three-axis compression.

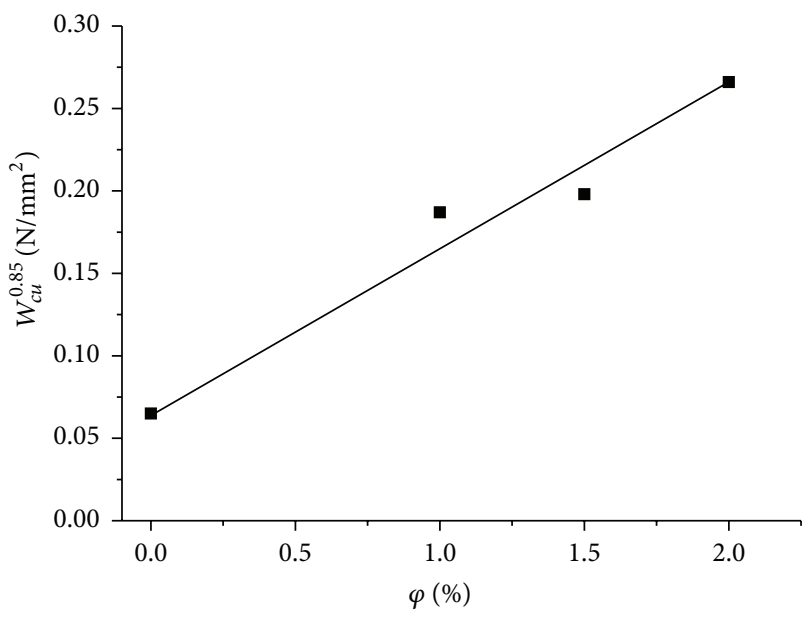

FIGURE 6: Relationship between equivalent compressive toughness index and volume ratio of PVA fiber.

For further analysis of the fiber bridging effect on HDC uniaxial compressive deformability, an equivalent analysis in what follows will study the lateral constraint effect and the stirrup constraint effect of HDC fiber bridging on the matrix. The confined concrete model proposed by Mander et al. [13] is adopted and an equivalent analysis is conducted to study the lateral constraint effect of HDC fiber bridging. The specific process is as follows.

The compressive peak strain of stirrup-confined concrete is

$$
\varepsilon_{c c o}=\varepsilon_{c o}\left[1+5\left(\frac{f_{c c}}{f_{c}}-1\right)\right] .
$$

In the formula, $\varepsilon_{c o}$ means the peak strain of concrete matrix; and $f_{c c}$ can be calculated through formula (6). Consider

$$
f_{c c}=f_{c}\left(-1.254+2.254 \sqrt{1+\frac{7.94 f_{t}}{f_{c}}}-\frac{2 f_{t}}{f_{c}}\right) .
$$

In this formula, $f_{t}$ means the lateral constraint stress caused by stirrups on concrete (matrix) and $f_{c}$ means the compressive strength of concrete (matrix).

The longitudinal compressive damage of concrete is caused by transverse cracking. During the compressive damage process of high ductile fiber reinforced concrete, vertical cracks caused by longitudinal compression and deformations caused by lateral tension of the specimen are confined by the fiber bridging effect of the internal matrix. Because of the tensile strain hardening effect of HDC, the specimen will continue to be subject to the sustained and stable transverse force after transverse cracking. Its mechanism is shown in Figure 7.

Assume that the transverse force on the HDC matrix under uniaxial compression (fiber bridging stress $\sigma_{t}$ ) does not exceed its tensile strength $f_{t}$. Based on the test results, take $\varepsilon_{c o}=0.0022$. The corresponding HDC tensile strength average $f_{t}=5.7 \mathrm{MPa}$ is obtained with the mix proportion as 4 , and the average value of the compressive strength of 
TABLE 4: The calculation results of equivalent compressive toughness.

\begin{tabular}{lccccccrrr}
\hline Mix & \multicolumn{3}{c}{ Compression } & $\Omega_{0.85}\left(\times 10^{5}\right)$ & $\Omega_{0.50}\left(\times 10^{5}\right)$ & $\Omega_{0.20}\left(\times 10^{5}\right)$ & $W_{c u}^{0.85}$ & $W_{c u}^{0.50}$ & $W_{c u}^{0.20}$ \\
\hline 1 & $\delta_{0.85}$ & $\delta_{0.50}$ & $\delta_{0.20}$ & 1.95 & 1.95 & 1.95 & 0.065 & 0.065 \\
2 & 0.65 & 0.65 & 0.65 & 5.60 & 6.26 & 7.02 & 0.065 \\
3 & 2.33 & 2.54 & 3.08 & 5.94 & 6.55 & 8.28 & 0.187 & 0.209 & 0.234 \\
4 & 2.14 & 2.31 & 3.48 & 7.99 & 9.68 & 11.46 & 0.218 & 0.276 \\
\hline
\end{tabular}

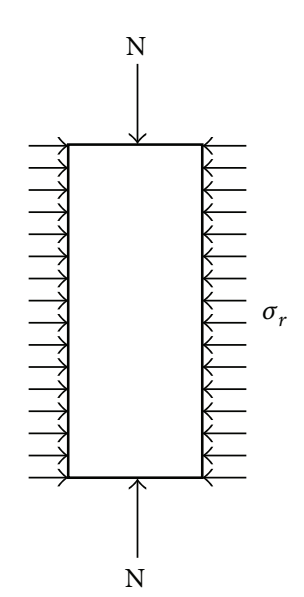

(a) External binding force that stirrups generated

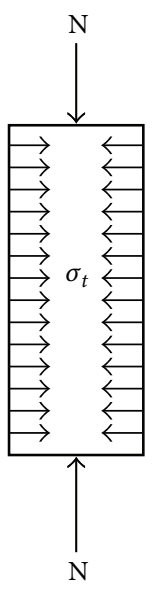

(b) Internal binding

force that fiber bridging

force

generated

FIgURE 7: Lateral binding force.

mortar matrix $f_{c}=63.06 \mathrm{MPa}$ is measured. Add $f_{t}, f_{c}$, and $\varepsilon_{c o}$ into formula (5) and formula (6), and the corresponding peak strain under HDC uniaxial compression $\varepsilon_{c c o}=0.0079$ is calculated with the mix proportion as 4 .

Obviously, according to the equivalent analysis of the transverse force resulting from the fiber bridging stress, the peak strain of the HDC specimen under uniaxial compression is up to 3.59 times as large as that of the mortar matrix, which is basically in line with our test result gained when the mix proportion is 4 .

In the following, the equivalent conversion relationship between fiber bridging stress $\sigma_{t}$ and transverse reinforcement ratio of confined concrete will be further analyzed.

As is shown by Figure 8, a balance equation can be formed by assuming that the fiber bridging stress and the stirrup binding force be equivalent:

$$
n A_{s v} f_{y v}=\sigma_{t} b s
$$

And formula (8) can be formed through formula (7). Consider

$$
s=\frac{n A_{s v} f_{y v}}{\sigma_{t} b} .
$$

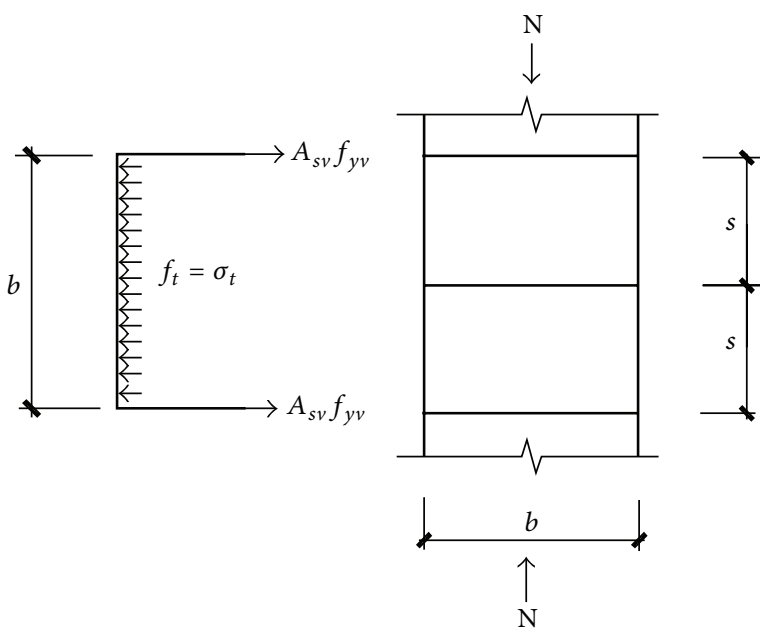

FIGURE 8: The equivalent of fiber bridging force and stirrup binding force.

Take a reinforced concrete column with a section size as $500 \mathrm{~mm} \times 500 \mathrm{~mm}$ as an example; an installed HRB400 stirrup is used with its diameter as $10 \mathrm{~mm}$ and thickness of protection layer as $25 \mathrm{~mm}$. So $b=450 \mathrm{~mm}, A_{s v}=78.5 \mathrm{~mm}^{2}$, and $n=2$. Then $\sigma_{t}=f_{t}=5.7 \mathrm{MPa}$, and $f_{y v}=360 \mathrm{~N} / \mathrm{mm}^{2}$, so $s=23 \mathrm{~mm}$ can be calculated through formula (8).

According to Code for design of concrete structures [11] in China, the equivalent volume stirrup ratio of rectangular column is

$$
\rho_{v}=\frac{n_{1} A_{s 1} l_{1}+n_{2} A_{s 2} l_{2}}{A_{c o r} s} .
$$

In this formula, $l_{1}=l_{2}=450 \mathrm{~mm}, A_{c o r}=202500 \mathrm{~mm}^{2}$, $A_{s 1}=A_{s 2}=78.5 \mathrm{~mm}^{2}$, and $n_{1}=n_{2}=2$. Via formula (9), the equivalent volume stirrup ratio corresponding to the HDC fiber bridging stress is $\rho_{v}=3.03 \%$, far higher than the requirement from framework and column-end dense area of stirrup installation ratio.

The abovementioned analyses suggest that the good tensile strain hardening effect of HDC and the fiber bridging binding effect of the internal matrix can prevent the emergence and development of micro cracks in the matrix, equivalent to a configuration of a large number of stirrups, thereby significantly increasing the specimen's deformability under uniaxial compression and showing a good compressive toughness. Therefore, the application of HDC in critical parts of the structure and components in plastic hinge region can 
not only markedly improve the deformability of plastic hinge region but also reduce the number of binding stirrups.

\section{Conclusion}

In this paper, three groups of uniaxial compressive tests of HDC specimens with different fiber mixing amounts have been conducted, arriving at the following preliminary conclusion:

(1) The peak strain of HDC under uniaxial compression can be up to 3.41 3.67 times as large as that of the mortar matrix and the specimens still have 10 20\% of residual bearing capacity during larger compressive deformations.

(2) The equivalent compressive toughness index $W_{c u}$ is used to reflect the unit volume deformation energy of specimens under uniaxial compression and it can be used as the compressive toughness evaluation index of specimens; with increasing fiber mixing amounts, the equivalent compressive toughness index of HDC specimens grows palpably.

(3) Though the fiber bridging effect of HDC does not markedly increase the uniaxial compressive strength, it does increase the equivalent compressive toughness index and the compressive deformability up to 3 times of the mortar matrix.

(4) The fiber mixing amount is a main factor that influences the HDC compressive toughness index and the relationship between the equivalent compressive toughness index $W_{c u}^{0.85}$ and the fiber mixing amount $\varphi$ is established according to the test results.

(5) It is showed by the equivalent analysis of the HDC fiber bridging stress and the constraint effect of stirrups that the HDC fiber bridging effect of the internal matrix, equaling a large number of constraint stirrups installed in the specimens, significantly enhances the compressive toughness and the compressive deformability of specimens.

\section{Conflict of Interests}

The authors declare that there is no conflict of interests regarding the publication of this paper.

\section{Acknowledgments}

The experimental work was carried out in the Structure Laboratory of the School of Civil Engineering, Xi'an University of Architecture and Technology, Shaanxi Province, China. The present work was financially supported by the Project of National Natural Science Foundation of Shaanxi Province, China (Grant no. 2013JM7013), and by the Innovation Team of Xi'an University of Architecture and Technology.

\section{References}

[1] V. C. Li and C. K. Y. Leung, "Steady-state and multiple cracking of short random fiber composites," Journal of Engineering Mechanics, vol. 118, no. 11, pp. 2246-2264, 1992.

[2] V. C. Li, H. Mihashi, and H. C. Wu, "Micromechanical models of mechanical response of HPFRCC," in High Performance Fiber Reinforced Cementitious Composites, Rilem Proceedings 31, A. E. Naaman and H. W. Reinhardt, Eds., pp. 43-100, 1996.

[3] C. X. Gong and J. Gong and Zhang, "Uniaxial tension behavior of high ductile fiber reinforced cementitious composite with focus on some influencing factors," Journal of Hydraulic Engineering, vol. 139, no. 3, pp. 361-366, 2008.

[4] J. Zhang, C.-X. Gong, X.-C. Ju, and Z.-L. Guo, "Bending performance of ductile fiber reinforced cementitious composite," Engineering Mechanics, vol. 27, no. 3, pp. 112-115, 2010.

[5] C. M. Pang, C. K. Y. Leung, and W. Sun, "Preparation and properties of high ductility cementitious composites with high content of fly-ash," Journal of the Chinese Ceramic Society, vol. 37, no. 12, pp. 2071-2077, 2009.

[6] H. D. Li and S. L. Xu, "High toughness cementitious composites bending properties and toughness evaluation method," Civil Engineering Journal, vol. 3, pp. 32-39, 2010.

[7] M. K. Deng, Y. T. Chang, and X. W. Liang, "Orthogonal test research on compressive strength size effect of engneered cementitious composites," Industrial Construction, vol. 7, pp. 80-85, 2013.

[8] M. K. Deng, H. Z. Sun, and X. W. Liang, "Experimental study of flexural behavior of ductile fiber reinforced concrete," Industrial Construction, vol. 5, pp. 85-90, 2014.

[9] X.-R. Cai and S.-L. Xu, "Experimental measurement and evaluation indexes of toughness properties for UHTCC under uniaxial compression," Engineering Mechanics, vol. 27, no. 5, pp. 218-239, 2010.

[10] S. L. Xu, X. R. Cai, and Y. H. Zhang, "Experimental measurement and analysis of the axial compressive stress-strain curve of ultra high toughness cementitious composites," Civil Engineering Journal, vol. 42, no. 11, pp. 79-85, 2009.

[11] GB 50010-2010: "Code for design of concrete structures".

[12] CECS, "Standard test methods for fiber reinforced concrete," CECS 13:2009, 2009.

[13] J. B. Mander, M. J. N. Priestley, and R. Park, "Theoretical stress-strain model for confined concrete," Journal of Structural Engineering, vol. 114, no. 8, pp. 1804-1826, 1988. 

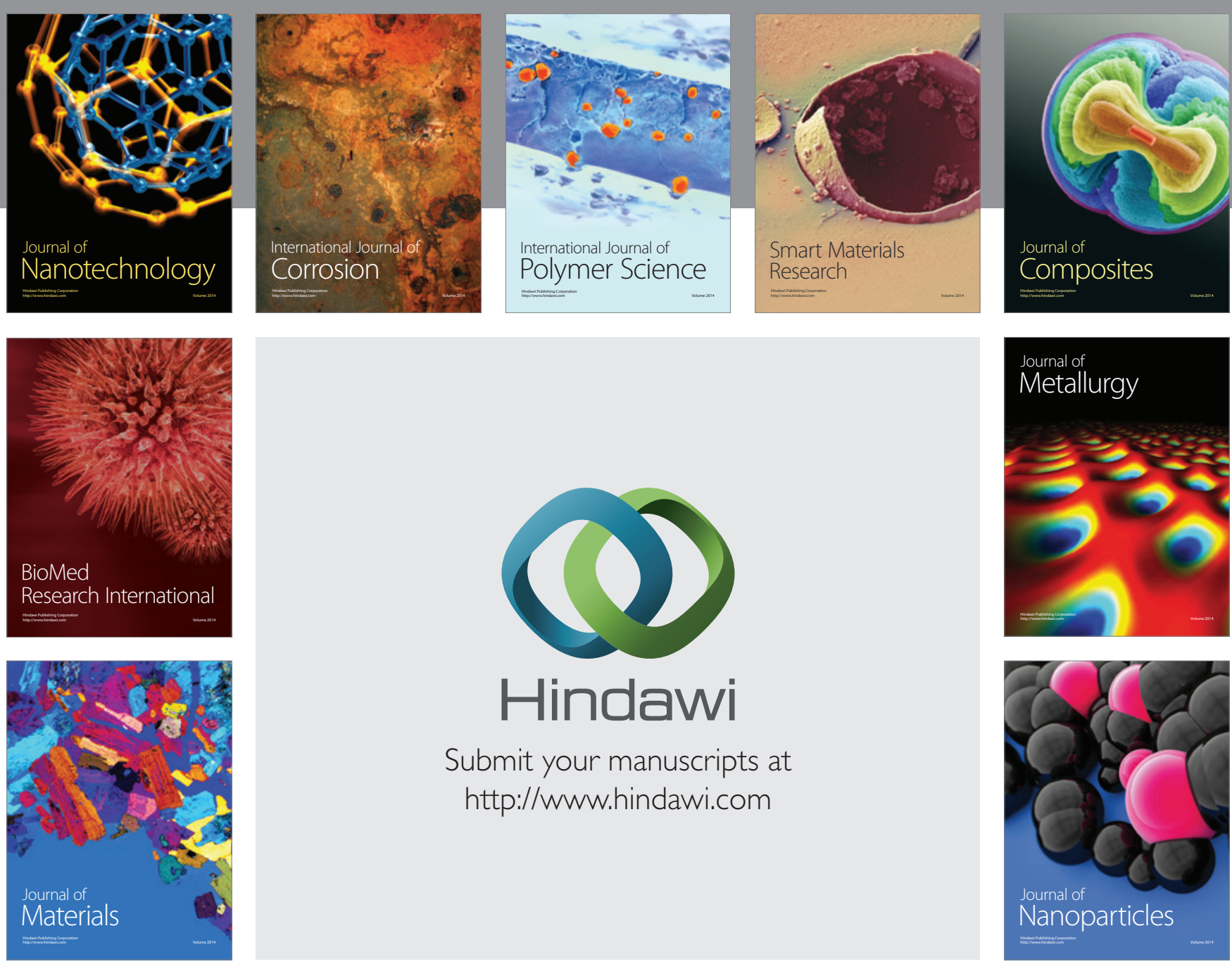

Submit your manuscripts at http://www.hindawi.com
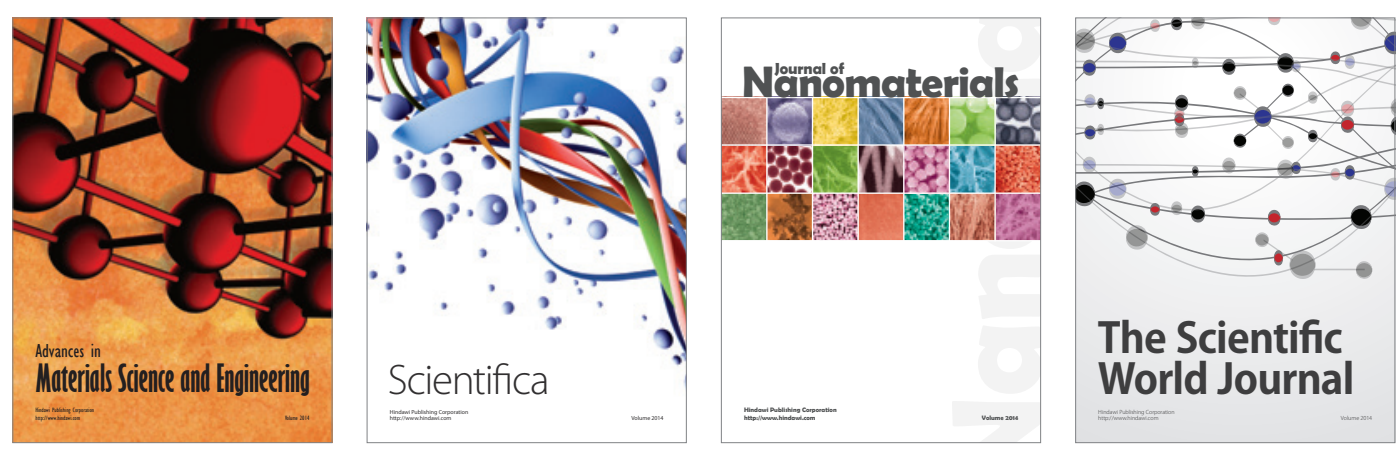

\section{The Scientific World Journal}
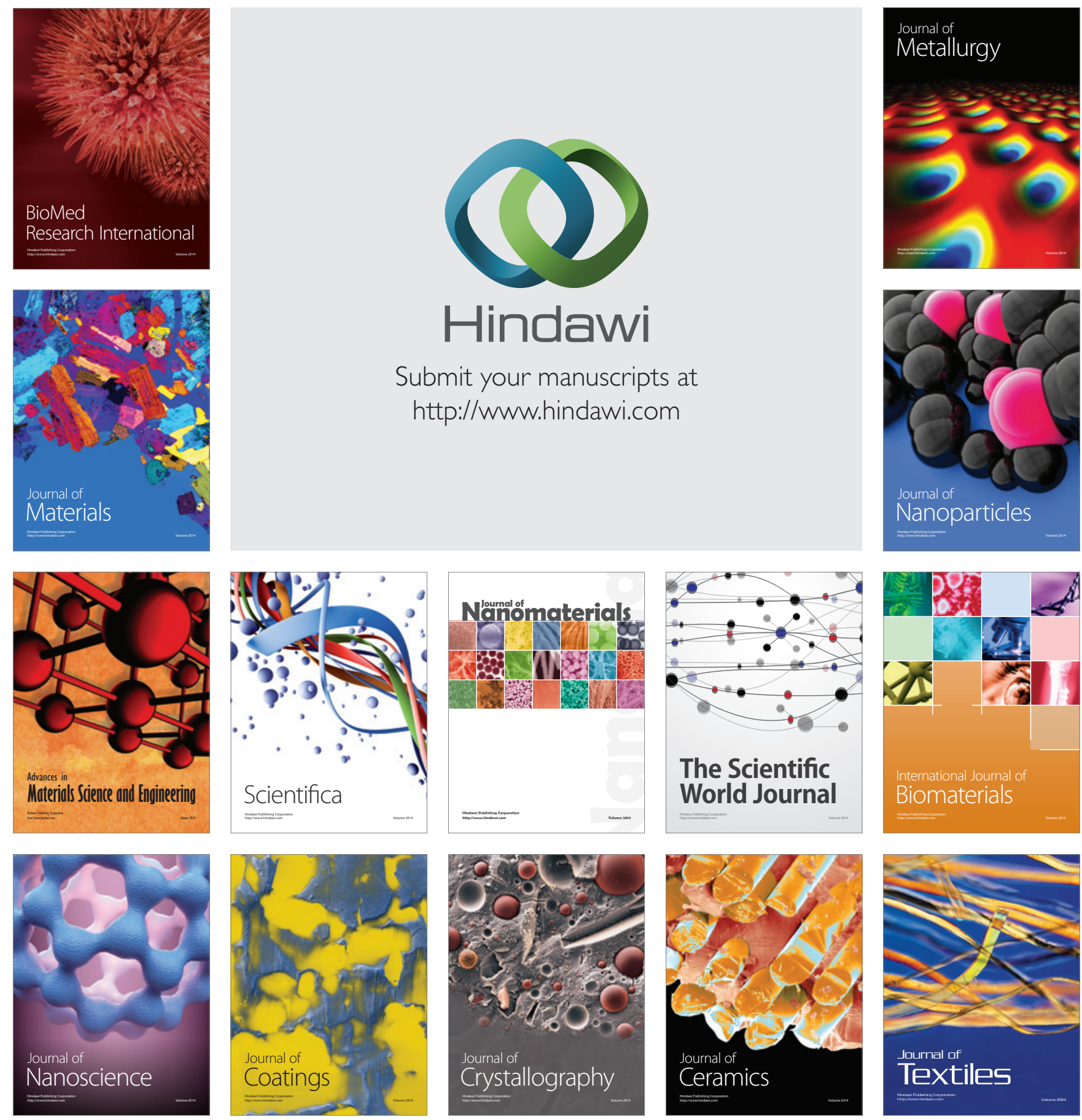